\title{
Neuromuscular Performance Characteristics in Elite Female Athletes*
}

\author{
Laura J. Huston, $\uparrow$ MS, and Edward M. Wojtys, MD
}

\author{
From MedSport, Section of Orthopaedic Surgery at the University of Michigan, \\ Ann Arbor, Michigan
}

\begin{abstract}
The purpose of this research was to identify possible predisposing neuromuscular factors for knee injuries, particularly anterior cruciate ligament tears in female athletes by investigating anterior knee laxity, lower extremity muscle strength, endurance, muscle reaction time, and muscle recruitment order in response to anterior tibial translation. We recruited four subject groups: elite female $(N=40)$ and male $(N=60)$ athletes and sex-matched nonathletic controls $(N=$ 40). All participants underwent a subjective evaluation of knee function, arthrometer measurement of anterior tibial translation, isokinetic dynamometer strength and endurance tests at 60 and $240 \mathrm{deg} / \mathrm{sec}$, and anterior tibial translation stress tests. Dynamic stress testing of muscles demonstrated less anterior tibial translation in the knees of the athletes (both men and women) compared with the nonathletic controls. Female athletes and controls demonstrated more anterior tibial laxity than their male counterparts and significantly less muscle strength and endurance. Compared with the male athletes, the female athletes took significantly longer to generate maximum hamstring muscle torque during isokinetic testing. Although no significant differences were found in either spinal or cortical muscle reaction times, the muscle recruitment order in some female athletes was markedly different. The female athletes appeared to rely more on their quadriceps muscles in response to anterior tibial translation; the three other test groups relied more on their hamstring muscles for initial knee stabilization.
\end{abstract}

During the 1989 to 1990 intercollegiate basketball season, the NCAA Injury Surveillance System reported that fe-

\footnotetext{
*Presented at the 22nd annual meeting of the AOSSM, Lake Buena Vista, Florida, June 1996.

†Address correspondence and reprint requests to Laura J. Huston, MS, Section of Orthopaedic Surgery at the University of Michigan, 24 Frank Lloyd Wright Drive, Ann Arbor, Ml 48106.

No author or related institution has received any financial benefit from research in this study.
}

male athletes injured their ACLs at a rate of 7.8 times more than their male counterparts. ${ }^{82}$ More recently, Malone et al. ${ }^{68}$ reported that collegiate female basketball players were eight times more likely to sustain ACL injuries compared with collegiate male basketball players. In 1994, Lindenfeld et al. ${ }^{66}$ reported that the injury rate for serious knee ligament injuries among female soccer players was 5.75 times that of male athletes. Consequently, this recent epidemic of severe knee injuries in women's sports has attracted considerable concern. $9,13,16,19,20,22,34,38,40,45,46,49,62,66,68,72,89,96,102,103,110$

In the past, it was difficult to study the incidence and distribution of injuries in women athletes because of the relatively small number participating in rigorous sports. However, since Title IX became law in 1972, the number of women participating in sports has increased dramatically. Women have ventured from traditional, noncontact sports, such as swimming and track and field, to physical games such as basketball, hockey (ice and field), and soccer. Paralleling this increase in participation by women has been an alarming rise in serious knee injuries, to at least twice the level seen in male athletes. $8,20,22,34,45,46,49,66,68,95,110$

Sports involving physical contact, jumping, sudden turning, and twisting are expected to produce knee ligament injuries, including ACL tears. However, even in noncontact sports, which are considered to pose less of a risk for knee ligament injury, Cox and Lenz ${ }^{11}$ and Jackson et al $^{46}$ reported a doubling of the injury rate among female athletes.

Based on the available data on injuries, we hypothesized that physiologic differences exist between men and women in knee joint laxity, lower extremity strength, endurance, muscle recruitment order, and muscle reaction time, and these differences are responsible for the disproportionate number of ACL injuries in women. The purpose of this research was to quantitate these differences by examining four groups: elite male and female athletes and nonathletic sex-matched controls. Examining these sex differences may eventually lead to a better understanding of the differences in knee injury rates between men and women. 


\section{MATERIALS AND METHODS}

\section{Subjects}

Forty healthy, active volunteers (26 men and 14 women; average age, 23.5 years) with no known knee abnormalities served as the control groups. The first 40 volunteers were tested. Athletic ability was not used as a selection criterion; the activity level of this group ranged from sedentary to recreational athletics. Forty Division I female athletes (10 basketball, 10 field hockey, 8 gymnastics, 12 volleyball) and 60 male college football players from the University of Michigan, Ann Arbor, Michigan, also with no known significant knee abnormalities, composed the elite athletic groups (average age, 19.7 years; range, 17 to 22 ). The authors considered a significant knee abnormality any condition that led to an operation or loss of more than a couple of days from regular practice. All members of these teams were asked to participate.

\section{Testing}

Each participant underwent a subjective evaluation of knee function and activity level, ${ }^{79}$ arthrometer measurement of anterior tibial translation, an isokinetic dynamometer (Biodex Medical Systems, Shirley, New York) strength and endurance test at 60 and $240 \mathrm{deg} / \mathrm{sec}$, and an anterior tibial translation stress test (Table 1). The anterior tibial translation stress test was designed to monitor lower extremity muscle function while tracking anterior tibial translation. The accuracy and reproducibility of this anterior tibial translation testing system has been reported. ${ }^{60,105}$

\section{Knee Testing Apparatus}

This device was designed to measure anterior tibial translation in reference to the femur in response to an anteriorly directed 30-pound step force applied to the proximal third of the posterior aspect of the leg (Fig. 1). ${ }^{105}$ Patients were seated on an ischial support that allowed uninhibited hamstring muscle function at $30^{\circ}$ of knee flexion, with the foot fixed at $10^{\circ}$ to $15^{\circ}$ of ankle dorsiflexion. Tibial motion was not restricted. Weightbearing status of the limb was monitored by a scale under the foot, and the scale was maintained in the range of 20 to 30 pounds. Relative anterior tibial translation was measured using two linear potentiometers. One potentiometer was placed

TABLE 1

Physical Activity Level Scale for Subjective Knee Evaluation

\begin{aligned} & \hline Score \multicolumn{1}{c}{ Activities } \\ & \hline 10 Competitive jumping, turning, twisting sports \\ & 8 Recreational jumping, turning, twisting sports \\ & 6 Jog, bike, swim, occasional pivoting sports \\ & 4 No jumping, turning, twisting sports; swim, bike, jog \\ & regularly \\ & 2 No jumping, turning, twisting; occasional jog, swim, bike \\ & 0 Inactive \\ & \hline\end{aligned}

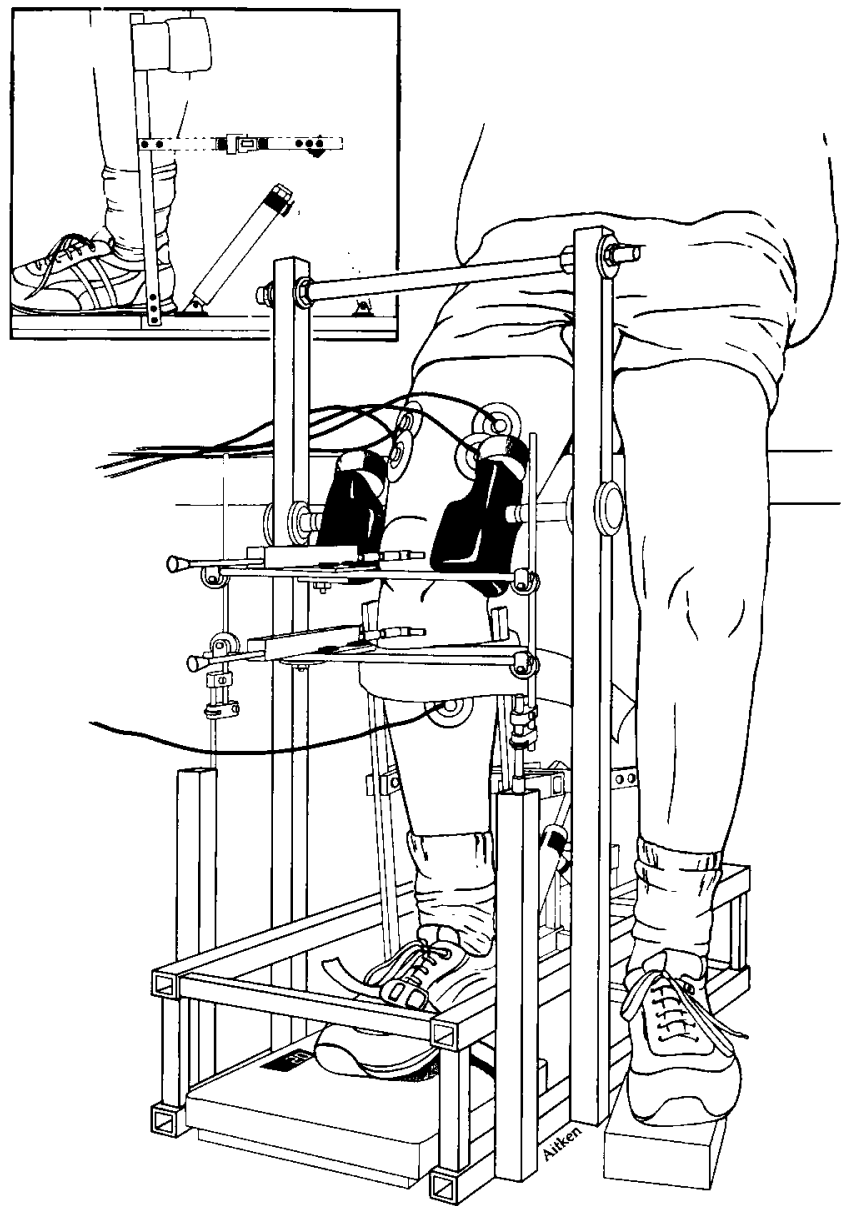

Figure 1. Stress testing device for anterior tibial translation testing. Surface EMG monitoring of the gastrocnemius, quadriceps, and hamstring muscles.

on the patella, and the other was placed on the tibial tuberosity (Fig. 1).

Lower extremity muscle function was recorded using surface EMG at five muscle locations: lateral and medial quadriceps, lateral and medial hamstring, and gastrocnemius. Bipolar surface electrodes, spaced $3 \mathrm{~cm}$ apart, were placed over the midregion of each muscle group, oriented along the muscle belly. Electromyographic recordings were sampled at a frequency rate of $1000 \mathrm{~Hz}$ during a 2.5 -second time frame, beginning 0.5 seconds before the onset of the anteriorly directed displacement force.

\section{Testing Protocol for Anterior Tibial Translation}

After an orientation session during which the anteriorly directed step force was applied several times to the posterior aspect of the proximal leg, two tests were performed. In the relaxed test, we asked subjects not to contract their quadriceps, hamstring, and gastrocnemius muscles in response to the anteriorly directed force. If muscle activity was detected on EMG at the start of the test, the trial was not used and the test was repeated. In the response test, we asked subjects to resist the anterior force as soon as 
they felt tibial movement. Ten trials of the relax and response muscle tests were recorded and the results were later averaged. We repeated any trial in which the subject contracted the leg musculature before the anterior force was applied. To prevent anticipation of force application, the authors used randomized time intervals that ranged from 0.1 to 10 seconds from the time the participant was ready to start. All visual and audio clues associated with the application of force were eliminated.

\section{Data Analysis}

Muscle reaction time was calculated by measuring the time delay between the onset of the 30-pound stimulus and the initiation of muscle activity. Three different muscle response segments (spinal reflex, intermediate, and voluntary muscle activities) were analyzed from each EMG signal.

Each segment of the EMG recording was identified by characteristic time of signal occurrence and signal shape. ${ }^{105}$ The spinal reflex is monosynaptic, using primary sensory afferents that resemble a tendon tap reflex on manual physical examination. However, spinal reflex does bypass muscle spindle receptors. ${ }^{52}$ The intermediate muscle response, which appears to be a spinal reflex with interneuronal input from centers higher than the spinal cord, resembles the late response produced electrically. ${ }^{18}$ This response is biphasic and routinely occurs just before voluntary activity. Voluntary muscle activity originates at supraspinal locations and was identified according to principles outlined by Kimura. ${ }^{52}$ These signals are usually twice as large in amplitude as the spinal reflex.

Anterior tibial laxity (arthrometer and the dual potentiometer system), isokinetic measurements of strength, endurance, time-to-peak torque (both at 60 and $240 \mathrm{deg} /$ sec), muscle reaction time, and muscle recruitment order preferences of the female athlete group were compared with the male athlete group and the female and male control groups.

\section{Statistics}

All data were analyzed by multifactor analysis of variance for repeated measures. Tukey's post hoc analysis was performed when three or more factors were present. The expected day-to-day measurement variability of the anterior tibial translation stress test and muscle reaction time was expressed by computing $95 \%$ confidence limits; the expected variations were then incorporated into the statistical analyses. Statistical significance was defined at $P<0.05$.

\section{RESULTS}

\section{Knee Laxity and Anterior Tibial Translation Comparisons}

Two predominant patterns emerged from the knee laxity data in the relaxed and response muscle tests: the knees of athletes were tighter than the knees of the nonathletic controls and the knees of women were looser than the knees of men (Table 2, Fig. 2). The female control group produced the greatest degree of anterior tibial translation in both the relaxed and response tests $(6.5$ and $3.0 \mathrm{~mm})$, and the male athlete group produced the least amount of anterior tibial translation in these tests ( 3.5 and $1.8 \mathrm{~mm}$ ). In both anterior tibial translation tests, the laxity found in the male athlete group was significantly less than that in the other three groups (female and male nonathlete controls and female athletes). Average anterior tibial translation (muscles relaxed trials) in the female athlete group was significantly less than in the male and female nonathletic controls $(4.5 \mathrm{~mm}$ compared with 5.8 and $6.5 \mathrm{~mm}$,

TABLE 2

Knee Laxity, Strength, Endurance, and Time-to-Peak Torque Comparisons Between Groups

\begin{tabular}{|c|c|c|c|c|}
\hline Variable & $\begin{array}{c}\text { Male } \\
\text { controls } \\
(N=26)\end{array}$ & $\begin{array}{c}\text { Female } \\
\text { controls } \\
(N=14)\end{array}$ & $\begin{array}{c}\text { Male } \\
\text { athletes } \\
(N=60)\end{array}$ & $\begin{array}{c}\text { Female athletes } \\
\quad(N=40)\end{array}$ \\
\hline \multicolumn{5}{|l|}{$\mathrm{ATT}(\mathrm{mm})^{\alpha}$} \\
\hline Relaxed & 5.8 & $6.5^{b}$ & $3.5^{c}$ & $4.5^{d}$ \\
\hline Contracted & 2.8 & $3.0^{b}$ & $1.8^{c}$ & 2.4 \\
\hline \multicolumn{5}{|l|}{ Isokinetic strength (\%BW) } \\
\hline Quadriceps & 88.4 & $72.5^{d}$ & $82.3^{c}$ & $76.7^{d}$ \\
\hline Hamstrings & 46.7 & $38.6^{d}$ & $48.3^{b e}$ & $40.9^{d}$ \\
\hline \multicolumn{5}{|l|}{$\begin{array}{l}\text { Isokinetic endurance } \\
\text { (\%BW) }\end{array}$} \\
\hline Quadriceps & 39.6 & $31.3^{b d}$ & $40.5^{b e}$ & $35.5^{d}$ \\
\hline Hamstrings & 20.5 & $16.5^{b d}$ & $22.6^{c}$ & 20.0 \\
\hline \multicolumn{5}{|l|}{ Time-to-peak torque (msec) } \\
\hline Quadriceps (60 deg/sec) & 463 & 448 & $408^{\text {de }}$ & $420^{d}$ \\
\hline Hamstrings $(60 \mathrm{deg} / \mathrm{sec})$ & 443 & 426 & $328^{c}$ & 430 \\
\hline Quadriceps (240 deg/sec) & 150 & 170 & $153^{e}$ & 158 \\
\hline Hamstrings (240 deg/sec) & 170 & 164 & $150^{c}$ & 169 \\
\hline
\end{tabular}

${ }^{a}$ ATT, anterior tibial translation.

${ }^{b}$ Significantly different from the female athletes $(P<0.05)$.

c Significantly different from all other groups $(P<0.05)$.

${ }^{d}$ Significantly different from the male controls $(P<0.05)$.

${ }^{e}$ Significantly different from the female controls $(P<0.05)$. 


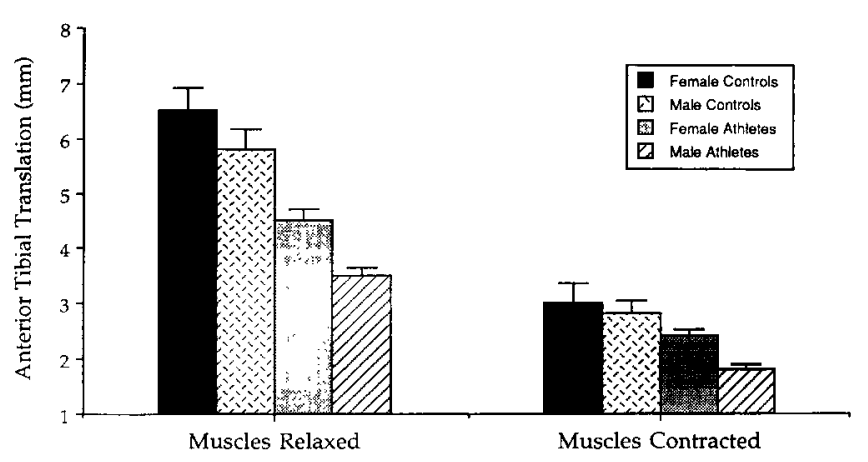

Figure 2. Anterior tibial translation comparisons.

respectively), but significantly greater than the male athletes $(3.5 \mathrm{~mm})$. Anterior tibial translation averages of female athletes in each sport (basketball, field hockey, gymnastics, and volleyball) were not significantly different from one another.

\section{Isokinetic Strength Comparisons}

The female control and athlete groups showed statistically weaker quadriceps and hamstring muscle strength at 60 $\mathrm{deg} / \mathrm{sec}$ compared with both the male control and athlete groups, even when normalized for body weight (footpounds torque/body weight[in pounds])(Table 2). Although there were no significant differences between the female controls and the female athletes in either knee extension or flexion peak torque, the female athletes generated slightly higher peak torques per body weight (quadriceps muscles, $76.7 \%$ versus $72.5 \%$; hamstring muscles, $40.9 \%$ versus $38.6 \%$ ).

Surprisingly, the male control group produced higher torques in both knee extension and flexion compared with the male athlete group (only knee extension was significant). This could be partially explained by the fact that many of the football players were large lineman.

\section{Isokinetic Endurance Comparisons}

Muscle endurance in both knee extension and flexion was better in the male and female athlete groups than in the male and female control groups (Table 2). However, even when normalized for body weight, both female groups produced significantly lower endurance rates compared with each male group.

\section{Neuromuscular Efficiency}

Time-to-Peak Torque at $60 \mathrm{deg} / \mathrm{sec}$. No significant differences in time-to-peak torque were seen in knee extension between either men and women or between athletes and nonathletes (Table 2, Fig. 3). However, significant differences were seen in the average knee flexion time-to-peak torque. The female athletes were an average of $102 \mathrm{msec}$ slower than the male athletes (430 versus $328 \mathrm{msec} ; P<$ 0.001 ) and minimally slower compared with the female control group ( 430 versus $426 \mathrm{msec}$ ). In sharp contrast,

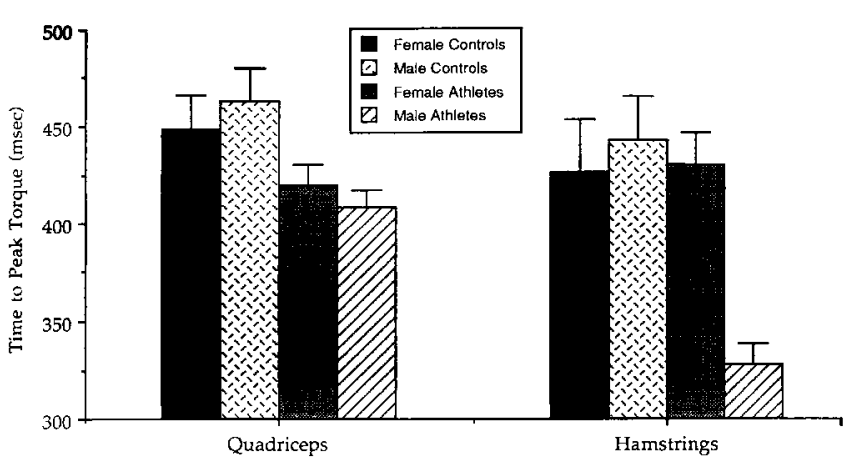

Figure 3. Time-to-peak torque data at $60 \mathrm{deg} / \mathrm{sec}$.

the male athletes were an average of $115 \mathrm{msec}$ faster compared with the male control group (328 versus 443 msec; $P<0.001$ ). No significant differences were found between the male and female control groups and the female athlete group.

Interestingly, the female athlete group was also the only group among the four groups to generate maximum torque in the hamstring muscle after generating maximum torque in the quadriceps muscle. The three other groups (female controls, male controls, male athletes) generated knee flexion peak torque 20 to $80 \mathrm{msec}$ before knee extension peak torque.

Time-to-Peak Torque at $240 \mathrm{deg} / \mathrm{sec}$. At $240 \mathrm{deg} / \mathrm{sec}$, the hamstring muscle group mirrored the time-to-peak torque pattern at $60 \mathrm{deg} / \mathrm{sec}$ (Table 2 , Fig. 4). The female athletes produced peak torque times in their hamstring muscles approximately equal to the female controls (169 versus $164 \mathrm{msec}$ ); yet, their times were significantly slower than the male athletes (169 versus $150 \mathrm{msec}$ ). No significant differences were found between the male and female nonathletic controls (170 versus $164 \mathrm{msec}$ ).

The female athletes generated maximum torque in the hamstring muscles an average of $11 \mathrm{msec}$ after the quadriceps muscle response, whereas the male athlete and control groups and the female control group generated hamstring muscle peak torque 3 to 6 msecs before the quadriceps muscles. This trend was consistent with the 60 $\mathrm{deg} / \mathrm{sec}$ speed.

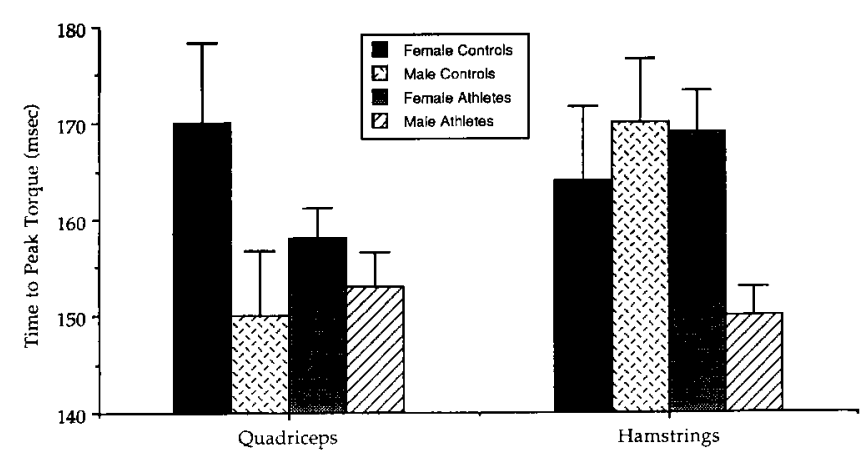

Figure 4. Time-to-peak torque data at $240 \mathrm{deg} / \mathrm{sec}$. 


\section{Muscle Reaction Time Comparisons}

Spinal Cord Level. No significant differences in muscle reaction times at the spinal cord level were found among the four groups in the medial and lateral quadriceps and hamstring muscles (Table 3). However, male and female athletes produced significantly faster gastrocnemius muscle responses compared with either control group (female athletes, $41.2 \mathrm{msec}$; female controls, $52.3 \mathrm{msec}$; male athletes, $41.6 \mathrm{msec}$; male controls, $51.2 \mathrm{msec}$ ).

Cortical Level. In the intermediate phase, no significant differences were found between any of the four groups tested (Table 3). However, the female athletes did respond faster than the female controls, male controls, and male athletes in each of the five muscle groups (lateral and medial quadriceps, lateral and medial hamstring, and gastrocnemius). The muscle reaction times of the females (controls and athletes) were generally faster than the male groups, but the difference was not statistically significant. Additionally, no significant differences were found in the voluntary response times within or between groups. The average muscle reaction time of the female athletes was faster than the male athletes and male controls in all muscle groups except for the lateral quadriceps muscle (female athletes, $244 \mathrm{msec}$; male controls, 230 $\mathrm{msec}$ ). The female control group produced the fastest voluntary muscle reaction time in all five muscle groups tested.

\section{Muscle Recruitment Order Preferences}

Spinal. All four groups most often recruited the gastrocnemius muscle first in response to anterior tibial translation, but the athletic groups (men, $88 \%$; women, $92 \%$ ) had significantly higher percentages compared with their nonathletic controls (men, 72\%; women, 67\%) (Table 3). In contrast, the athlete groups used their hamstring muscles first much less frequently ( $1 \%$ to $6 \%$ ) than the male and female controls $(14 \%)$. This same pattern was seen in quadriceps muscle recruitment; the athlete groups recruited this muscle group much less frequently (6\% to $7 \%$ ) than the nonathletic control groups (16\%). All groups favored a gastrocnemius-hamstring-quadriceps muscle pattern, with the exception of the volleyball players (gastrocnemius-quadriceps-hamstring muscle pattern). This muscle group pattern is the normal response to anterior tibial translation, according to Wojtys and Huston. ${ }^{105}$

Intermediate. The increased initial quadriceps muscle activity and the decreased initial hamstring muscle activity in the female athlete characterizes the intermediate phase. Both male groups and the female controls preferred to use the hamstring muscles initially for knee stabilization (male controls, $47 \%$; male athletes, $45 \%$; female controls, $43 \%$ ); the female athletes relied primarily on the quadriceps muscles $(47 \%)$. To stabilize their knees, the female athletes relied on the hamstring muscles first in only $28 \%$ of the trials. The nonathletic controls $(28 \%)$

TABLE 3

Average Spinal and Cortical Level Muscle Reaction Times (milliseconds) and Muscle Recruitment Order

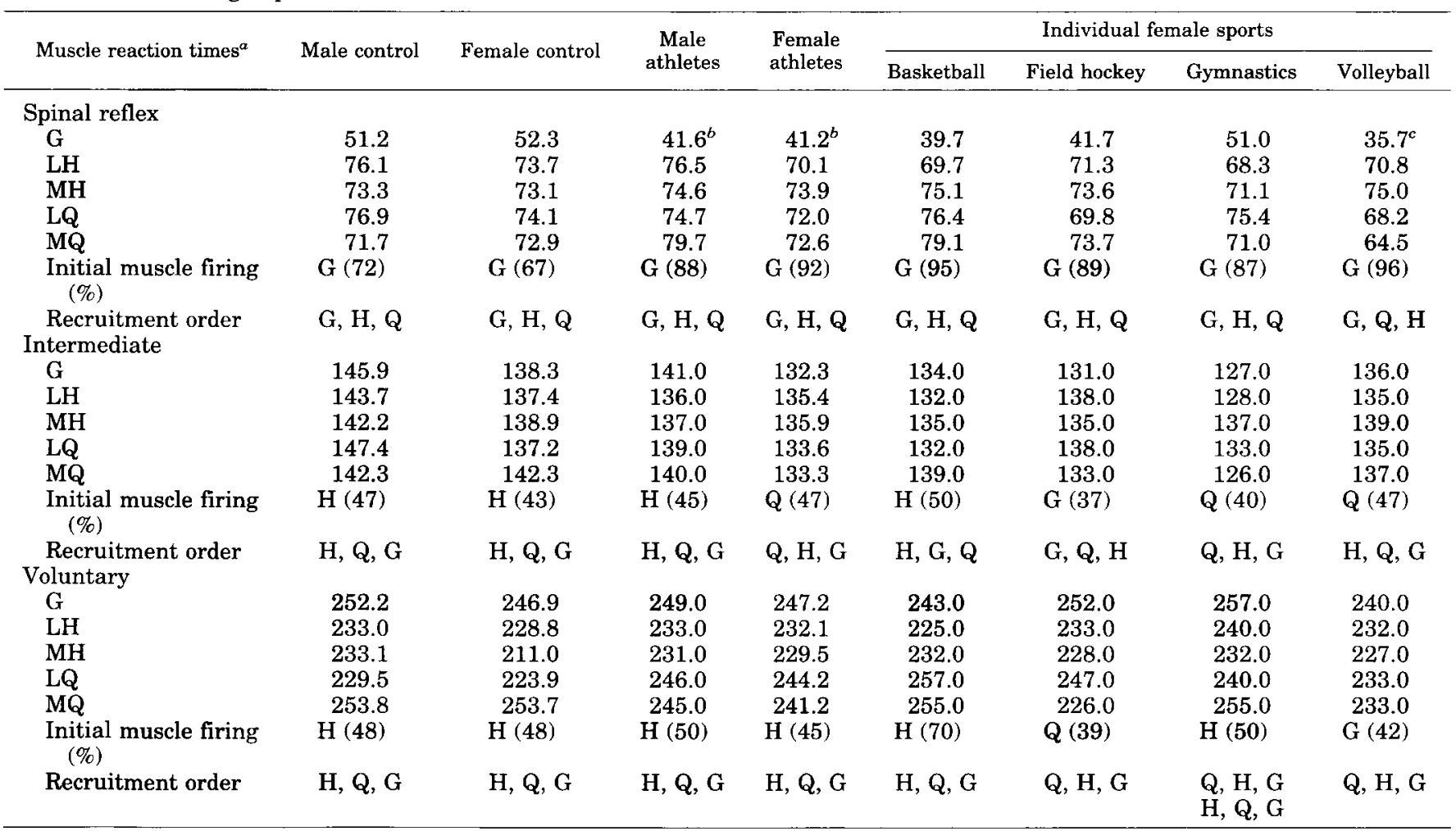

${ }^{a} \mathrm{G}$, gastrocnemius; LH, lateral hamstring; $\mathrm{MH}$, medial hamstring; LQ, lateral quadriceps; MQ, medial quadriceps muscles.

${ }^{b}$ The muscle reaction times of the male and female athletes were significantly different from the male and female control groups.

c The muscle reaction times of female volleyball players were significantly different from those of female gymnasts. 
relied on the quadriceps muscles much less than the male and female athletes (45\% and $47 \%$, respectively).

The predominant muscle recruitment order of the male athletes and the male and female controls was the hamstring-quadriceps-gastrocnemius muscle pattern, and the predominant muscle recruitment order of the female athletes was the quadriceps-hamstring-gastrocnemius muscle pattern. Volleyball was the only female sport with a predominant recruitment order consistent with the female control group and both male groups (i.e., hamstring-quadriceps-gastrocnemius muscle pattern).

Voluntary. The predominant voluntary muscle recruitment order in female athletes was identical to the male and female control groups and the male athletes (hamstring-quadriceps-gastrocnemius muscle pattern). Interestingly, the male and female athletes relied on their hamstring muscles as much as their nonathletic controls (range, $45 \%$ to $50 \%$ ) during the voluntary muscle response phase.

Overall, the female athletes showed a muscle recruitment order pattern similar to the nonathletic controls. Interestingly, the male athlete group exhibited a lower percentage of initial quadriceps muscle recruitment (17\%) and increased gastrocnemius muscle activity (33\%) compared with the nonathletic male and female control groups (quadriceps muscles, 35\%; gastrocnemius muscles, 17\%).

\section{Correlation between Quadriceps and Hamstring Muscle Strength and Muscle Reaction Time}

The muscle reaction times from five subjects with the highest quadriceps and hamstring muscle peak torque values (as determined by isokinetic dynamometer testing) were compared with those from subjects with the five lowest peak torque values to determine if higher levels of lower extremity muscle strength correlated with faster muscle reaction times. All torque values (in foot-pounds) were normalized for body weight (in pounds). The same protocol was used for the five highest and lowest torques produced from the hamstring muscles. No strong correlations were found between the muscle reaction time and the strength of the quadriceps and hamstring muscles. This finding is consistent for the spinal level and cortical level responses (intermediate, voluntary).

\section{DISCUSSION}

The ACL is the primary static restraint to anterior tibial translation. However, equally important to functional knee joint stability is the dynamic role muscles play in preventing anterior translation of the tibia. In a potential injury situation, such as a deceleration maneuver or a lateral blow to the knee, the lower extremity muscles, in particular the hamstring muscles, can potentially relieve ACL strain. ${ }^{86}$ Evidence for this phenomenon is witnessed daily. Forces generated across the knee during activities of daily living frequently exceed 1 to 2 times body weight. ${ }^{87}$ Sports activities increase these forces in excess of 5 times body weight. ${ }^{71}$ Studies of ligament failure have shown that ligaments acting alone would not be able to withstand these levels of loading. ${ }^{80,107}$ Dynamic muscle stabilization protects knee joints, allowing knees to withstand such stress and strain. Knee joint surface geometry, the menisci, and secondary ligament stabilizers also play a role in functional stability, but those roles are minor compared with the stabilization provided by the quadriceps, hamstring, and gastrocnemius muscles at the knee.

Laboratory proof of this dynamic protection for ligaments is considerable. White and Raphael ${ }^{101}$ demonstrated the protective effect of quadriceps muscle contraction on the medial collateral ligament during valgus loading. Goldfuss et al ${ }^{28}$ reported a $48 \%$ increase in the stiffness of the medial side of the knee with the contraction of the quadriceps and hamstring muscles. Wang and Walker ${ }^{100}$ decreased rotational laxity at the knee by $80 \%$ with a $938 \mathrm{~N}$ compressive load applied across the knee. Markolf et al. ${ }^{69}$ used athletes to document a 10 -fold increase in knee joint stiffness with muscle contraction. These studies demonstrate that dynamic muscle stabilization of the tibiofemoral joint is a powerful component of knee joint stability and needs to be considered in any investigation of knee ligament injury or failure.

When the function of the ACL in controlling anterior tibial translation is considered, the hamstring muscle, in particular, becomes of interest. In a classic study using Hall effect transducers, Renström et al. ${ }^{86}$ demonstrated the shielding effect that the hamstring muscles have on the ACL. Walla et al., ${ }^{99}$ Draganich et al., ${ }^{15}$ Hagood et al., ${ }^{35}$ and Solomonow et al. ${ }^{93}$ have reported similar findings: the hamstring muscles work in concert with the ACL to control anterior tibial translation.

The activity of the hamstring muscles in vivo is balanced by the quadriceps muscle, an ACL antagonist. The quadriceps muscle, however, averages $50 \%$ to $100 \%$ greater strength than the hamstring muscle. Unopposed quadriceps muscle contractions could translate the tibia anteriorly and cause significant strain in the ACL, especially from $30^{\circ}$ of knee flexion to full extension. ${ }^{44,86}$ Therefore, the "balance of power" between the quadriceps and hamstring muscles is crucial to normal knee function because the quadriceps muscles can produce forces in excess of those needed for ligament tensile failure. ${ }^{105}$

This balance of muscle power is maintained by a neuromuscular servomechanism that modulates quadriceps and hamstring muscle activities. The neuromuscular servomechanism appears to be controlled through afferent input originating in the ACL. ${ }^{29,50,83,92}$ Although the exact neurocircuitry of this system remains under investigation, there is increasing evidence that alpha motoneurons are affected by both high ${ }^{17,18}$ and low ${ }^{43}$ threshold joint afferents. Flexor reflex pathways, ${ }^{18}$ Ia interneurons, ${ }^{21,31}$ and Ib interneurons ${ }^{67}$ have a modulating affect on efferent pathways. Failure of this complex dynamic servomechanism, which appears to depend on multiple sources of afferent input, could explain the rise in noncontact ACL injuries reported in rigorous sport activities today.

The first evidence of this growing problem of ACL injuries in female athletes surfaced in 1975 when Gillette ${ }^{25}$ conducted a questionnaire survey on athletic injuries throughout the United States and reported that the inci- 
dence of knee injuries was highest in women's basketball, volleyball, field hockey, and gymnastics. Surprisingly, Garrick and Requa ${ }^{24}$ reported that women's gymnastics ranked third behind football and wrestling as a leading producer of injuries at the interscholastic level. In 1990, Ireland and Wall ${ }^{45}$ studied 144 basketball athletes at the U.S. Olympic trials through a history questionnaire and found that significant knee injuries had occurred in 11 of 80 men $(13 \%)$ and in 34 of 64 women $(53 \%)(P<0.0001)$. Ferretti et al. ${ }^{22}$ reported a much higher frequency of knee ligament injuries in female volleyball players than in their male counterparts, with 48 of $52(92 \%)$ of these injuries related to jumping. Interestingly, the increased risk for injury appears to begin early in life. Gray et al. ${ }^{34}$ reported that adolescent female basketball players were five times more likely to rupture their ACLs compared with male basketball players.

Currently, only limited physiologic data is available that might explain the causes of ACL injury in women. Isolated knee laxity measurements ${ }^{2,33,47,77}$ and lower extremity strength profiles $1,6,8,10,12,14,23,26,30,32,39,41$, $42,48,51,53,57,59,76,78,81,85,88,91,94,97,108$ are part of this injury equation, but thus far clinicians have not identified the source of the problem. More physiologic data are needed before a meaningful analysis of this injury can be attempted. This biomechanical analysis exposes physiologic differences that may contribute to ACL injury among women athletes.

Other investigators have identified important components of dynamic knee function without reference to sex. Beard et al. ${ }^{3}$ defined the proprioceptive functions necessary to successfully protect ligaments: static awareness of joint position in space, kinesthetic awareness (movement and acceleration), and closed-loop efferent activity for reflex response and regulation of muscle stiffness across joints. In this investigation, joint function was challenged by suddenly translating the tibia anteriorly from a resting position during a stress test. The lower extremities then responded in a stabilizing manner to prevent anterior tibial translation. The muscle reaction time parameter is an indicator of how well these induced changes in joint position are detected and how quickly the quadriceps, hamstring, and gastrocnemius muscles can be mobilized in response to the perturbation. Although the quadriceps and hamstring muscles have long been recognized as important determinants of knee joint function, the gastrocnemius muscle has only recently been identified as an important knee joint stabilizer. ${ }^{64,105}$

As Table 3 indicates, there were no significant differences between the female athletes and the nonathletic control groups in terms of spinal or cortical muscle reaction times. However, differences in the female athletes appeared when the muscle recruitment preference data was examined. In the intermediate phase, $28 \%$ of the female athletes preferred to recruit their hamstring muscles first in response to anterior tibial translation compared with $45 \%$ of the male athletes, $45 \%$ of the male controls, and $45 \%$ of the female controls. During the voluntary phase of muscle reaction time, $31 \%$ of female athletes recruited their quadriceps muscle first compared with only $17 \%$ of the male athletes. This apparent decrease in hamstring muscle use and increase in initial quadriceps muscle contraction in response to anterior tibial translation could place an increased level of strain on the $\mathrm{ACL}^{86}$ and render the ligament more susceptible to injury.

Another component of the neuromuscular response during joint stabilization is the time required to generate peak muscle torque once the protective muscle contraction has been initiated. The time interval required to reach maximum capacity appears to be an important injury prevention parameter. ${ }^{3,37,90,109}$ At the slower isokinetic testing speed $(60 \mathrm{deg} / \mathrm{sec})$, male and female athletes generated peak knee extension torques before their sexmatched controls. Most importantly, the male athletes generated peak torque in knee flexion substantially faster than the male controls ( 328 versus $443 \mathrm{msec}$ ), but the female athletes were no faster than the female controls (430 versus $426 \mathrm{msec}$ ). The female athletes were substantially slower than male athletes in generating peak knee flexion torques. These results parallel other studies that have found sex differences in the rate of muscle force production. ${ }^{5,36,58,65,98,104}$ In these studies, women required significantly more time than men to produce the same relative muscle force levels. Komi and Karlsson ${ }^{58}$ and Winter and Brookes ${ }^{104}$ have suggested that this lower rate of force development in women is the result of structural differences in the series elastic component of muscle.

In the current study, the electromechanical delay of muscle in women was most noticeable in the hamstring muscle. The female athlete group was the only group that generated maximum knee flexion torque after maximum knee extension torque. This may mean that the quadriceps muscles of some female athletes outperform their hamstring muscles. Because the female controls did not demonstrate this pattern of quadriceps muscle dominance, the training and conditioning programs in these female sports are suspect. A muscle response pattern to anterior tibial translation dominated by the quadriceps muscle appears to be present and deserves further investigation. Furthermore, we need to answer the question: Is this pattern induced by current training methods in female sports or just due to inadequate conditioning?

Careful review of the muscle testing data shows that the five strongest female athletes (based on quadriceps and hamstring peak torque results) used a voluntary muscle recruitment order favoring the initial use of the hamstring muscles in response to anterior tibial translation; the five weakest female athletes used the quadriceps muscles initially. This factor suggests that adequate lower extremity muscle conditioning may be the key to establishing the time sequence for muscle recruitment. If this "quadriceps first" trend is found in larger groups of female athletes, a critical review of today's approach to training female athletes is warranted; a muscle rebalancing, conditioning program for the lower extremity appears to be a rational first step for female athletes playing high-risk sports.

The concept of balancing the quadriceps and hamstring muscles is not new, although previous efforts have primarily focused on progressive resistance exercise. Recent 
research has emphasized the importance of agility training while questioning the role of traditional strength training. ${ }^{106}$ With training, muscle use patterns have been successfully altered in female athletes. ${ }^{40}$ In women volleyball players, adduction moments on landing after jumps were decreased after 6 weeks of intense training and conditioning.

The female athletes participating in this study competed in Division I NCAA sports, in which the training and conditioning programs are sophisticated and among the best available in this country. Unfortunately, even when corrected for body weight, the strength levels of these women do not match those achieved by men (Table 2 ). This strength deficit may be due to several factors. Female athletes may not be able to perform at the same levels based on physiologic differences in skeletal muscle characteristics $4,5,36,58,65,70,73,98,104$ or hormone fluctuations. ${ }^{7,61,74}$ Also, the training and conditioning that occurred at earlier levels of competition may not have been as rigorous. Although current training programs at the university level are similar in opportunity, those at the high or middle school levels or even earlier may not be equal. If the problem is a deficit in early training, then the current emphasis on women's sports should correct this problem. If, however, women are substantially different physiologically, then male conditioning programs may not be the answer, and further research may be needed to address these issues.

Although there was a statistically significant difference in the anterior tibial laxity profile of men and women, it is unknown whether the statistical difference detected is a relevant clinical factor in ACL injury (Fig. 2). Joint hypermobility and the extremes of anterior tibial translation are known to be more prevalent in women than in men. ${ }^{54,63,84}$ Understandably, several studies have attempted to correlate injury prevalence with excess ligamentous laxity. Nicholas ${ }^{77}$ suggested a strong correlation between "loose-jointedness" and the frequency of joint injury; this correlation has been supported by Acasuso-Diaz et al. ${ }^{2}$ and Kibler et al., ${ }^{51}$ who reported increased injury rates. However, contradictory reports by Godshall, ${ }^{27}$ Grana and Moretz, ${ }^{33}$ Jackson et al., ${ }^{47}$ Knapik et al., ${ }^{55,56}$ Meeuwisse and Fowler, ${ }^{72}$ and Moretz et al..$^{75}$ have shown no direct relationship between ligamentous laxity and the frequency or type of knee injury.

The anterior tibial translation data from this study suggest that the knees of men are tighter than those of women (Fig. 2). If the ability to control anterior tibial translation with hamstring muscle contractions that subsequently relieve strain on the ACL is a learned response, then male athletes appear to be more successful with the currently used training and conditioning programs. However, the physiologic complexity of female neuromuscular function may not be adequately appreciated and, more importantly, current athletic programs may not accommodate female needs. Further research is needed to investigate these issues in female sports. Based on future research, athletic programs may need to be redesigned with special consideration given to the physiology of women.

\section{CONCLUSIONS}

1. Although no differences were found in either spinal cord or cortical level muscle reaction times, the order of muscle recruitment in response to anterior tibial translation in the female athletes was significantly different. Female athletes relied more on the quadriceps and gastrocnemius muscles to resist anterior tibial translation. The male groups recruited the hamstring muscle for initial knee stabilization more frequently.

2 . The female athletes took significantly longer to produce hamstring peak torque $(430 \mathrm{msec})$ than the male athletes (328 msec) during isokinetic testing.

3. Even when normalized for body weight, female athletes showed considerably weaker knee extension and flexion strength compared with both male groups. Female athletes were only minimally stronger than their nonathletic female counterparts.

4. Female athletes had significantly poorer endurance rates compared with both male control and athletic groups. However, the endurance rates were significantly better compared with the nonathletic female controls.

5. Higher levels of lower extremity muscle strength (quadriceps and hamstring muscles) did not correlate with shorter muscle reaction times. Conversely, poor lower extremity muscle strength did not correlate with longer muscle reaction times.

6. In general, the knees of women had greater laxity than the knees of men, and the knees of the athletes were tighter than the knees of the nonathletic controls. The female athlete group exhibited statistically higher anterior tibial translation $(4.5 \mathrm{~mm})$ compared with the male athlete group (3.5 $\mathrm{mm})$, but this result was significantly lower than the nonathletic male $(5.8 \mathrm{~mm})$ and female $(6.5$ $\mathrm{mm}$ ) control groups.

\section{ACKNOWLEDGMENTS}

The authors thank Sandip Kothari and Brad Wylie for their technical assistance and the athletic trainers and athletes at the University of Michigan, Ann Arbor, Michigan.

\section{REFERENCES}

1. Abbott HG, Kress JB: Preconditioning in the prevention of knee injuries. Arch Phys Med Rehabil 50: 326-333, 1969

2. Acasuso-Diaz M, Collantes-Estevex E, Sanchez-Guijo PS: Joint hyperlaxity and musculoligamentous lesions: Study of a population of homogeneous age, sex, and physical exertion. Br J Rheumatol 32: 120-122, 1993

3. Beard DJ, Dodd CAF, Trundle HR, et al: Proprioception enhancement for anterior cruciate ligament deficiency. J Bone joint Surg 76B: $654-65 \overline{9}$, 1994

4. Behm DG, Sale DG: Voluntary and evoked muscle contractile characteristics in active men and women. Can J Appl Physiol 19: 253-265, 1994

5. Bell DG, Jacobs I: Electro-mechanical response times and rate of force development in males and females. Med Sci Sports Exerc 18: 31-36, 1986

6. Berg K, Blanke D, Miller M: Muscular fitness profile of female college basketball players. J Orthop Sports Phys Ther 7: 59-64, 1985

7. Bonen A, Haynes FW, Graham TE: Substrate and hormonal responses to exercise in women using oral contraceptives. $J$ Appl Physiol 70: 1917-1927, 1991 
8. Cahill BR, Griffith EH: Effect of preseason conditioning on the incidence and severity of high school football knee injuries. Am J Sports Med 6: $180-184,1978$

9. Clarke KS, Buckley WE: Women's injuries in collegiate sports. A preliminary comparative overview of three seasons. Am $J$ Sports Med 8 : 187-191, 1980

10. Costain R, Williams AK: Isokinetic quadriceps and hamstring torque levels of adolescent, female soccer players. J Orthop Sports Phys Ther 5: $196-200,1984$

11. Cox JS, Lenz HW: Women in sports: The Naval Academy experience. Am J Sports Med 7: 355-357, 1979

12. Davies GJ, Kirkendall DT, Leigh DH, et al: Isokinetic characteristics of professional football players: Normative relationships between quadriceps and hamstring muscle groups and relative to body weight. Med SCi Sports Exerc 13: 76-77, 1981

13. DeHaven KE, Lintner DM: Athłetic injuries: Comparison by age, sport, and gender. Am J Sports Med 14: 218-224, 1986

14. DiBrezzo R, Gench BE, Hinson MM, et al: Peak torque values of the knee extensor and flexor muscles of females. J Orthop Sports Phys Ther 7: $65-68,1985$

15. Draganich $L F$, Jaeger $R$, Kralj $A$ : EMG activity of the quadriceps and hamstrings during monoarticular knee extension and flexion. Trans Orthop Res Soc 12: 283,1987

16. DuRant RH, Linder CW, Sanders JM Jr, et al: Adolescent females' readiness to participate in sports. Sex and race differences in the preparticipation athletic examination. J Adolesc Health Gare 9: 310-314, 1988

17. Eccles JC: Evolution of the Brain. New York, Routledge, 1989, pp 61-67

18. Eccles $R$, Lundberg A: Synaptic actions in motoneurons by afferents which may evoke the flexion reflex. Arch Ital Biol 97: 199-221, 1959

19. Eisenberg I, Allen WC: Injuries in a women's varsity athletic program. Physician Sportsmed 6(3): 112-120, 1978

20. Engström B, Johansson $C$, Törnkvist $H$ : Soccer injuries among elite female players. Am J Sports Med 19: 372-375, 1991

21. Fedina $L$, Hultborn $H$ : Facilitation from ipsilateral primary afferents of interneuronal transmission in the la inhibitory pathway to motoneurones. Acta Physiol Scand 86: 59-81, 1972

22. Ferretti $A$, Papendrea $P$, Conteduca $F$, et al: Knee ligament injuries in volleyball players. Am J Sports Med 20: 203-207, 1992

23. Fleck SJ, Falkel JE: Value of resistance training for the reduction of sports injuries. Sports Med 3: 61-68, 1986

24. Garrick JG, Requa RK: Injuries in high school sports. Pediatrics 61: 465-469, 1978

25. Gillette JV: When and where women are injured in sports. Physician Sportsmed 7(5): 61-63, 1975

26. Gilliam TB, Sady SP, Freedson PS, et al: Isokinetic torque levels for high school football players. Arch Phys Med Rehabil 60: 110-114, 1979

27. Godshall RW: The predictability of athletic injuries: An eight-year study. $J$ Sports Med 3: 50-54, 1975

28. Goldfuss AJ, Morehouse CA, LeVeau BF: Effect of muscular tension on knee stability. Med Sci Sports 5: 267-271, 1973

29. Gómez-Barrena E, Munuera L, Martinez-Moreno E: Neural pathways of anterior cruciate ligament traced to the spinal ganglia. Trans Orthop Res Soc 17: 503, 1992

30. Goslin BR, Charteris J: Isokinetic dynamometry: Normative data for clinical use in lower extremity (knee) cases. Scand $J$ Rehabil Med 11: 105-109, 1979

31. Goslow GE Jr, Reinking RM, Stuart DG: The cat step cycle: Hind limb joint angles and muscle lengths during unrestrained locomotion. J Morphol 141: 1-4t, 1973

32. Grace TG, Sweetser ER, Nelson MA, et al: Isokinetic muscle imbalance and knee-joint injuries. J Bone Joint Surg 66A: 734-740, 1984

33. Grana WA, Moretz JA: Ligamentous laxity in secondary school athletes. JAMA 240: 1975-1976, 1978

34. Gray J, Taunton JE, McKenzie DC, et al: A survey of injuries to the anterior cruciate ligament of the knee in female basketball players. Int $J$ Sports Med 6: 314-316, 1985

35. Hagood S, Solomonow M, Baratta $\mathrm{R}$, et al: The effect of joint velocity on the contribution of the antagonist musculature to knee stiffness and laxity. Am J Sports Med 18: 182-187, 1990

36. Hakkinen K: Force production characteristics of leg extensor, trunk flexor and extensor muscles in male and female basketball players. $J$ Sports Med Phys Fitness 31: 325-331, 1991

37. Hakkinen K, Pakarinen A, Kallinen M: Neuromuscular adaptations and serum hormones in women during short-term intensive strength training. Eur J Appl Physiol 64: 106-111, 1992

38. Haycock CE, Gillette JV: Susceptibility of women athletes to injury. Myths vs reality. JAMA 236: 163-165, 1976

39. Hejna WF, Rosenberg A, Buturusis DJ, et al: The prevention of sports injuries in high school students through strength training. Natl Strength Condition Assoc J 4: 28-31, 1982
40. Hewett TE, Stroupe AL, Nance TA, et al: Increased performance, decreased landing forces, and increased hamstrings power in young female athletes with jump training. Am J Sports Med, in press, 1996

41. Holloway JB, Baechle TR: Strength training for female athletes: A review of selected aspects. Sports Med 9:216-228, 1990

42. Holmes JR, Alderink GJ: Isokinetic strength characteristics of the quadriceps femoris and hamstring muscles in high school students. Phys Ther 64: $914-918,1984$

43. Hongo $T$, Jankowska $E$, Lundberg $A$ : The rubrospinal tract. II. Facilitation of interneuronal transmission in reflex paths to motoneurons. Exp Brain Res 7: 365-391, 1969

44. Howe JG, Wertheimer C, Johnson RJ, et al: Arthroscopic strain gauge measurement of the normal anterior cruciate ligament. Arthroscopy 6 : 198-204, 1990

45. Ireland ML, Wall C: Epidemiology and comparison of knee injuries in elite male and female United States basketball athletes. Med Sci Sports Exerc 22: $\$ 82,1990$

46. Jackson DS, Furman WK, Berson BL: Patterns of injuries in college athletes: A retrospective study of injuries sustained in intercollegiate athietics in two colleges over a two-year period. Mt Sinai J Med 47: 423-426, 1980

47. Jackson DW, Jarrett $H$, Bailey $D$, et al: Injury prediction in the young athlete: A preliminary report. Am J Sports Med 6: 6-14, 1978

48. Jones RE: Common athletic injuries in women. Compr Ther 6(9): 47-49, 1980

49. Kannus $P$, Nittymaki $S$, Jarvinen $M$ : Sports injuries in women: A oneyear prospective follow-up study at an outpatient sports clinic. $B r J$ Sports Med 21: 37-39, 1987

50. Kennedy JC, Alexander IJ, Hayes KC: Nerve supply of the human knee and its functional importance. Am J Sports Med 10: 329-335, 1982

51. Kibler WB, Chandler TJ, Uhl T, et al: A musculoskeletal approach to the preparticipation physical examination. Preventing injury and improving performance. Am J Sports Med 17: 525-531, 1989

52. Kimura J: Electrodiagnosis in Diseases of Nerve and Muscle: Principles and Practice. Second edition. Philadelphia, FA Davis Co, 1989

53. Klein KK: Muscular strength and the knee. Physician Sportsmed 2(12): $29-31,1974$

54. Klemp $P$, Stevens JE, Isaacs $S$ : A hypermobility study in ballet dancers. $J$ Rheumatol 11: 692-696, 1984

55. Knapik JJ, Bauman $\mathrm{CL}$, Jones $\mathrm{BH}$, et al: Preseason strength and flexibility imbalances associated with athletic injuries in female collegiate athletes. Am J Sports Med 19: 76-81, 1991

56. Knapik JJ, Jones $B \mathrm{H}$, Bauman $\mathrm{CL}$, et al: Strength, flexibility, and athletic injuries. Sports Med 14: 277-288, 1992

57. Knight KL: Strength imbalance and knee injury. Physician Sportsmed $8(1): 140,1980$

58. Komi PV, Karlsson J: Skeletal muscle fibre types, enzyme activities and physical pertormance in young males and females. Acta Physiol Scand 103: $210-218,1978$

59. Kowal DM: Nature and causes of injuries in women resulting from an endurance training program. Am J Sports Med 8: 265-269, 1980

60. Kowalk DL, Wojtys EM, Disher J, et al: Quantitative analysis of the measuring capabilities of the KT-1000 ligament arthrometer. Am J Sports Med 21: 744-747, 1993

61. Laessle RG, Tuschl RJ, Schweiger U, et al: Mood changes and physical complaints during the normal menstrual cycle in healthy young women. Psychoneuroendocrinology 15(2): 131-138, 1990

62. Lanese $R R_{r}$ Strauss $R H$, Leizman DJ, et al: Injury and disability in matched men's and women's intercollegiate sports. Am J Public Health 80: $1459-1462,1990$

63. Larsson LG, Baum J, Mudholkar GS: Hypermobility: Features and differential incidences between the sexes. Arthritis Rheum 30:1426-1430, 1987

64. Lass P, Kaalund S, leFevre S, et al: Muscle coordination following rupture of the anterior cruciate ligament. Electromyographic studies of 14 patients. Acta Orthop Scand 62: 9-14, 1991

65. Lennmarken C, Bergman T, Larsson J, et al: Skeletal muscle function in man: Force, relaxation rate, endurance and contraction time-dependence on sex and age. Clin Physiol 5: 243-255, 1985

66. Lindenfeld TN, Schmitt DJ, Hendy MP, et al: Incidence of injury in indoor soccer. Am J Sports Med 22: 364-371, 1994

67. Lundberg A, Malmgren K, Schomburg ED: Role of joint afferents in motor control exemplified by effects on reflex pathways from $\mathrm{lb}$ afferents. $J$ Physiol 284: 327-343, 1978

68. Malone TR, Hardaker WT, Garrett WE, et al: Relationship of gender to anterior cruciate ligament injuries in intercollegiate basketball players. $J$ South Orthop Assoc 2: 36-39, 1993

69. Markolf KL, Mensch JS, Amstutz HC: Stiffness and laxity of the kneethe contributions of the supporting structures. A quantitative in vitro study. J Bone Joint Surg 58A: 583-594, 1976

70. Maughan RJ, Watson JS, Weir J: Strength and cross-sectional area of human skeletal muscle. J Physiol 338: 37-49, 1983 
71. McNitt-Gray JL, Yokoi T: Kinetics of the lower extremities during drop landings from three heights. J Biomech 26: 1037-1046, 1993

72. Meeuwisse WH, Fowler PJ: Frequency and predictability of sports injuries in intercollegiate athletes. Can J Sports Sci 13: 35-42, 1988

73. Miller AE, MacDougall JD, Tarnopolsky MA, et al: Gender differences in strength and muscle fiber characteristics. Eur J Appl Physiol 66: 254262, 1993

74. Möller-Nielson J, Hammar M: Women's soccer injuries in relation to the menstrual cycle and oral contraceptive use. Med Sci Sports Exerc 21: 126-129, 1989

75. Moretz JA, Walters R, Smith L: Flexibility as a predictor of knee injuries in college football players. Physician Sportsmed 10(7): 93-97, 1982

76. Morrow JR, Hosler WW: Strength comparisons in untrained men and trained women athletes. Med Sci Sports Exerc 13: 194-198, 1981

77. Nicholas JA: Injuries to knee ligaments: Relationship to looseness and tightness in football players. JAMA 212: 2236-2239, 1970

78. Nicholas JJ, Robinson LR, Logan A, et al: Isokinetic testing in young nonathletic able-bodied subjects. Arch Phys Med Rehabil 70: 210-213, 1989

79. Noyes FR, Barber SD, Mangine RE: Bone-patellar figament-bone and fascia lata allografts for reconstruction of the anterior cruciate ligament. $J$ Bone Joint Surg 72A: 1125-1136, 1990

80. Noyes FR, Grood ES: The strength of the anterior cruciate ligament in humans and rhesus monkeys. J Bone Joint Surg 58A: 1074-1082, 1976

81. Parker MG, Ruhling RD, Holt D, et al: Descriptive analysis of quadriceps and hamstrings muscle torque in high school football players. $J$ Orthop Sports Phys Ther 5: 2-6, 1983

82. Pearl AJ: The Athletic Female. Champaign, IL, Human Kinetic Publishers, 1993, pp 302-303

83. Pitman MI, Nainzadeh N, Menche D, et al: The intraoperative evaluation of the neurosensory function of the anterior cruciate ligament in humans using somatosensory evoked potentials. Arthroscopy 8: 442-447, 1992

84. Powers JA: Characteristic features of injuries in the knee in women. Clin Orthop 143: 120-124, 1979

85. Rankin JM, Thompson CB: Isokinetic evaluation of quadriceps and hamstrings function: Normative data concerning body weight and sport. Ath/ Training 18: 110-114, 1983

86. Renström $P$, Arms SW, Stanwyck TS et al: Strain within the anterior cruciate ligament during hamstring and quadriceps activity. Am J Sports Med 14: 83-87, 1986

87. Röhrle $H$, Scholten $R$, Sigolotto $C$, et al: Joint forces in the human pelvis-leg skeleton during walking. J Biomech 17: 409-424, 1984

88. Roundtable: Strength training and conditioning for the female athlete. Natl Strength Condition Assoc $J$ 7(3): 10-29, 1985

89. Rubin CJ: Sports injuries in the female athlete. $N J$ Med 88(9): 643-645, 1991

90. Ryushi T, Hakkinen $\mathrm{K}$, Kauhanen $\mathrm{H}$, et al: Muscle fiber characteristics muscle cross-sectional area and force production in strength athletes, physically active males and females. J Sports Sci 10(1): 7-15, 1988
91. Schlinkman B: Norms for high school football players derived from Cybex data reduction computer. J Orthop Sports Phys Ther 5: 243-245, 1984

92. Schutte MJ, Dabezies EJ, Zimny ML, et al: Neural anatomy of the human anterior cruciate ligament. J Bone Joint Surg 69A: 243-246, 1987

93. Solomonow $\mathrm{M}$, Baratta $\mathrm{R}, \mathrm{Zhou} \mathrm{BH}$, et al: The synergistic action of the anterior cruciate ligament and thigh muscles in maintaining joint stability. Am J Sports Med 15: 207-213, 1987

94. Stone $\mathrm{MH}$ : Muscle conditioning and muscle injuries. Med Sci Sports 22 : 457-462, 1990

95. Taimela S, Kujala UM, Osterman K: Intrinsic risk factors and athletic injuries. Sports Med 9: 205-215, 1990

96. Tenvergert EM, Ten Duis $H J$, Klasen $H J$ : Trends in sports injuries 1982-1988: An in-depth study on four types of sport. J Sports Med Phys Fitness 32(2): 214-220, 1992

97. Thomas LE: Isokinetic torque levels for adult females: Effects of age and body size. J Orthop Sports Phys Ther 6: 21-24, 1984

98. Viitasalo JT, Komi PV: Force-time characteristics and fiber composition in human leg extensor muscles. Eur J Appl Physiol 40: 7-15, 1978

99. Walla DJ, Albright JP, McAuley $E$, et al: Hamstring control and the unstable anterior cruciate ligament-deficient knee. Am J Sports Med 13 $34-39,1985$

100. Wang CJ, Walker PS: Rotatory laxity of the human knee joint. J Bone Joint Surg 56A: 161-170, 1974

101. White AA 3rd, Raphael IG: The effect of quadriceps loads on knee position on strain measurements of the tibial collateral ligament. An experimental study on human amputation specimens. Acta Orthop Scand 43: 176-187, 1972

102. Whiteside PA: Men's and women's injuries in comparable sports. Physician Sportsmed 8(3): 130-140, 1980

103. Wilmore JH: The female athlete. J Sch Health 47: 227-233, 1977

104. Winter EM, Brookes FB: Electromechanical response times and muscle elasticity in men and women. Eur J Appl Physiol 63(2): 124-128, 1991

105. Wojtys EM, Huston LJ: Neuromuscular performance in normal and anterior cruciate ligament-deficient lower extremities. Am J Sports Med 22. 89-104, 1994

106. Wojtys EM, Huston LJ, Taylor PD, et al: Neuromuscular adaptations in isokinetic, isotonic, and agility training programs. Am J Sports Med, in press, 1996

107. Woo SLY, Hollis JM, Adams DJ, et al: Tensile properties of the human femur-anterior cruciate ligament-tibia complex. The effects of specimen age and orientation. Am J Sports Med 19:217-225, 1991

108. Wyatt MP, Edwards AM: Comparison of quadriceps and hamstring torque values during isokinetic exercise. $J$ Orthop Sports Phys Ther 3 . 48-56, 1981

109. Yasuda $\mathrm{K}$, Erickson AR, Johnson RJ, et al: Dynamic strain behavior in the medial collateral and anterior cruciate ligaments during lateral impact loading. Trans Orthop Res Soc 17: 127, 1992

110. Zelisko JA, Noble HB, Porter M: A comparison of men's and women's professional basketball injuries. Am J Sports Med 10: 297-299, 1982 